\title{
US Defense Department destroys evidence of Vietnam devastation
}

\author{
Alastair Hay reports on a row in the US over the loss of \\ photographs used in the much disputed NAS report on the \\ effects of herbicides during the Vietnam war
}

Photographic evidence, used by the US National Academy of Sciences (NAS) for its 1974 report on the effects of herbicides in South Vietnam has been destroyed by the Department of Defense (DoD). According to Dr Thomas Dashiell, staff specialist for chemical technology at the DoD, the photographs were destroyed "in late 1977 through the spring of 1978 ".

Estimates of the acreage of forest sprayed with herbicides and the number of trees killed as a result of the spraying were based on these aerial photographs. Hundreds of rolls of film for the period 1958-1973 were examined by the Academy in order to assess the extent of the damage. Dr Philip Handler, president of the NAS, told Nature that most of the photographs were "taken by or in cooperation with the Department of Defense and were studied at the College of Forest Resources, University of Washington".

Dr James Bethel, Dean of the College of Forest Resources, was in charge of that study. His initial estimate of "merchantable timber" killed by herbicides was considered too low by a review panel and the figure was revised upwards before the NAS report was published. The report estimated that some $5 \times 10^{5}$ to $2 \times 10^{6}$ cubic metres of merchantable timber had been killed out of a total of $8.5 \times 10^{6}$ cubic metres sprayed. Spraying had in fact affected $10.3 \%$ of inland forests, $36.1 \%$ of mangrove forests, $3.2 \%$ of cultivated land and $5.5 \%$ of other vegetation.

Publication of these figures by the Academy created a storm of protest in scientific circles. Accusations that the estimates were too low were made by several scientists. Two members of the NAS committee reviewing the herbicide issue, Professor Paul Richards of the University College of North Wales and Professor Pham-Hoang Hô, University of Saigon, both dissented from the report on these grounds. Hô claimed that the estimates were out by an order of magnitude, a view which was supported by Professor Mathew Meselson of Harvard University and a member of the report's review panel. Meselson also claimed that the figures were 10 times too low.

The charges that the estimates were inaccurate were rejected by the NAS committee chairman, Professor Anton
Lang of Michigan State University. His reply to Hô's dissenting letter considered it "quite impossible" that the figures in the report could be out by the order of magnitude suggested.

Few NAS reports have created as much discord as this one. For this reason alone, many scientists argue that the evidence used by the NAS for the compilation of its report ought to have been kept. Dr Dashiell disagrees. He told Nature that the Department of Defense feels that "the NAS committee report represents a complete and well documented analysis of any ecological or environmental effects to the forests in South Vietnam". This, he says, was the principle reason for the study, and the photography provided for the committee study "represented only one means to reach their conclusions".

Dashiell says that the photography was kept for a longer period than originally envisaged. Following publication of the report, the photographs were placed in a repository at the University of Washington for use by scientists interested in doing further work on them.

This arrangement was approved by Dr Handler for the NAS, with the provision that a review be conducted after 12 months to determine whether the material be retained or destroyed. In the event, Dashiell points out, the material was left in the repository for two years, after which it was returned to the DoD where it remained for a further year before being destroyed. According to Dashiell, the scientific community "showed no interest during the lengthy time allowed for any review of their effort".

There is one scientist who was interested in these photographs and who is incensed about their destruction. Meselson, an outspoken critic of the NAS report, is in the process of compiling his own report about herbicide damage in Vietnam. In 1970, Meselson led a team of scientists to Vietnam on behalf of the American Association for the Advancement of Science (AAAS). Government officials in the White House, State and Defense Departments had advance warning of the team's preliminary report to the 1970 December meeting of the AAAS. A short time after this, an order was issued by the White House curtailing the use of

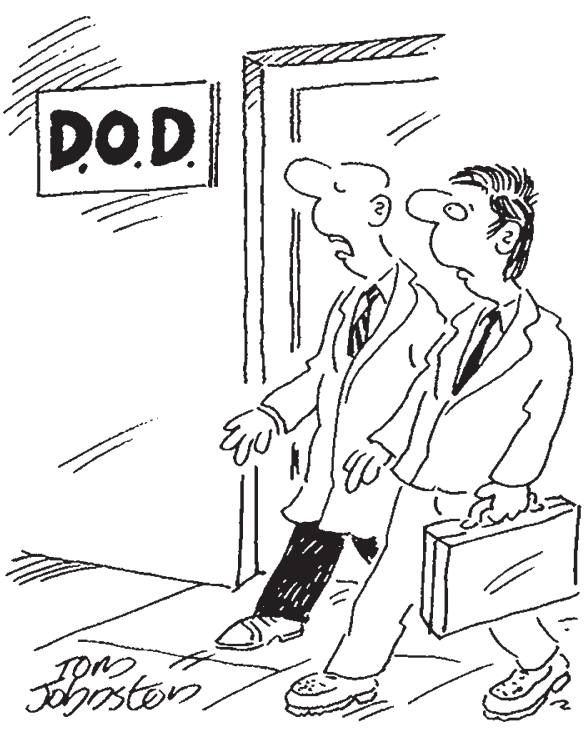

" $I t$ means 'Destroy Offensive Documents'!"

herbicides in Vietnam.

A summary of the AAAS findings were published in the Congressional Record on 3 March, 1972, but a final, fuller report of the team's investigations has never been written. Meselson has been chided in private on this point, but he told Nature that he hoped to be able to write the report this summer. One of the reasons for his delay was that he wanted to see the controversy surrounding the publication of the NAS report die down. This, he hoped, would give him an opportunity to produce his own report challenging the NAS estimates of timber damage on purely scientific grounds. Meselson makes no secret of the fact that the DoD's action in destroying the photographs has not made his job any easier.

Another reason advanced by the DoD justifying destruction of the photographs also seems rather lame. Dashiell insists that there were "physical storage problems" with the 35,000 items at the University of Washington repository so the decision was made to return the photography to the custody of the DoD. The story as related by Bethel at Washington University is slightly different. Bethel makes no reference to storage problems but says that, as no inquiries had been received about the photographs, he was "instructed by the Academy to return the photographs to the Department of Defense". According to Bethel, it was his understanding that the material was to be destroyed.

It seems, however, that although some probably irreplaceable scientific evidence has been destroyed, all is not lost; according to Dashiell, when the photographs were destroyed, the silver was recovered in accordance with "legislative mandates"! 